\title{
APAGAMENTO DA OCLUSIVA DENTAL NO DIALETO DO BREJO PARAIBANO: UMA REGRA VARIÁVEL
}

\author{
Rubens Marques de Lucena ${ }^{1}$ \\ Dennise Cunha de Vasconcelos ${ }^{2}$
}

Resumo: A presente pesquisa, fundamentada no modelo teórico da sociolingǘstica quantitativa, versa sobre o apagamento da oclusiva dental /d/ nos grupos "ndo", na língua falada na região do Brejo da Paraíba. Os dados foram extraídos de um corpus composto por registros de fala de 6 informantes residentes naquela região. As entrevistas, gravadas em situações naturais de interação social, foram realizadas com base em questões voltadas para os interesses de cada informante, de acordo com as informações contidas em uma ficha social. Em seguida, os dados coletados foram submetidos a um tratamento computacional, através do software GOLDVARB X. Como resultados preliminares, o software apontou as seguintes variáveis como relevantes para o fenômeno em estudo: classe de palavras, sexo e contexto fonético-fonológico anterior. Além disto, observou-se que há maior ocorrência da manutenção da oclusiva dental /d/ na fala dos informantes.

Palavras-chave: Variação lingüística, Apagamento fonológico, Língua falada.

Abstract: This paper, based on the theoretical framework of quantitative sociolinguistics, aims at understanding the process of /d/ deletion in 'ndogroups' in the speech community of Brejo da Paraiba, Brazil. The data were collected from an oral language corpus which represents the dialect spoken in that community. The interviews, recorded in a natural conversation situation, were based on the speaker's favorite talk subjects, according to a preinterview, previously arranged. The data were then submitted to a statistic treatment, through GOLDVARB X software. The preliminary results indicated that the factors 'word class', 'sex' and 'preceeding phonological context' were relevant to the phenomenon.

Key words: Linguistic variation, Phonological deletion, Spoken language.

\section{INTRODUÇÃO}

Desde a década de 1970, vêm sendo produzidos trabalhos científicos importantes, sobretudo na área de sociolingüística variacionista, que procuram entender a língua portuguesa falada no Brasil. Com respeito aos falares locais, é possível citar os trabalhos desenvolvidos no PEUL, da UFRJ, no Rio de Janeiro; pelo VARSUL,

1 Professor Titular de Lingüística no Curso de Letras da Universidade Estadual da Paraíba UEPB (Campus III - Guarabira). Endereço eletrônico: rubenslucena@yahoo.com.

2 Graduanda em Letras, bolsista do Programa Institucional de Iniciação Científica da UEPB (PROINCI/UEPB), sob a orientação do Prof. Dr. Rubens Marques de Lucena; graduanda em Comunicação Social pela Universidade Federal da Paraíba - UFPB. 
envolvendo os três estados da Região Sul e pelo VALPB, da UFPB, na cidade de João Pessoa.

Poucos estudos, no entanto, têm-se voltado para o interior do Brasil, principalmente no que diz respeito à Região Nordeste. Esta pesquisa objetiva, portanto, preencher esta lacuna: entender melhor a língua portuguesa do interior do Nordeste, mais especificamente a língua falada na região do Brejo Paraibano. A região paraibana do Brejo abrange um território de aproximadamente três mil km² e tem, em sua composição, as seguintes cidades: Alagoa Grande, Alagoinha, Araçagi, Belém de Caiçara, Cuitegi, Duas Estradas, Guarabira, Gurinhém, Ingá, Itatuba, Juarez Távora, Lagoa de Dentro, Mulungu, Pilõezinhos, Serra da Raiz e Serra Redonda. Destas cidades, a maior é Guarabira, que funciona como pólo local.

O fenômeno lingüístico focado nesta pesquisa é o apagamento da oclusiva dental /d/ nos grupos "ndo", que consiste na assimilação do fonema /d/ pelo fonema /n/ e é constituído de duas variantes: a) presença da oclusiva dental, quando o informante a realiza em finais de palavras como "comendo", "cantando"; b) ausência da oclusiva, isto é, o apagamento, como em "comeno", "cantano".

\section{AbordagenS SOBRE O TEMA}

O fenômeno da redução /nd/ $>/ \mathrm{n} /$ não é um processo novo dentro da história da língua portuguesa. Silva Neto (1970, p. 43), por exemplo, acusa a variação em todas as partes do Brasil, salientando que "a mudança de /nd/ para /n/ [...] como assimilação é possível de se verificar em qualquer espaço ou tempo, mas que, por singular coincidência, ocupam áreas homogêneas no norte da Península Ibérica e no sul da Itália". O fenômeno também pode ser observado no estado atual de línguas de origem latina e em línguas crioulas.

Melo (1946, p. 90-91) afirma que o apagamento da oclusiva é bastante produtivo na fala popular da região de Goiás e na região nordestina. Embora alguns autores sustentem que a queda da oclusiva é o resultado da influência indígena e africana, Melo acredita que não existe nenhuma correlação, uma vez que a redução /nd/ > /n/ existe em outras línguas alheias à intervenção do tupi ou línguas de origem africana.

No que se refere a pesquisas de cunho variacionista, o fenômeno de apagamento da oclusiva foi anteriormente estudado por Mollica e Mattos (1989), com o português falado na cidade do Rio de Janeiro. Nesse estudo, a autora detectou que substantivos, adjetivos e advérbios favorecem a manutenção da oclusiva. Os verbos no gerúndio, por outro lado, favorecem o apagamento. Outro fator de importância observado pela autora foi a extensão do item lexical: quanto maior o número de sílabas, maior a probabilidade de apagamento na fala espontânea.

Com relação aos fatores extralingüísticos, o estudo demonstrou que a escolaridade e o sexo do informante eram relevantes para o comportamento variável do 
apagamento da oclusiva. No caso da escolaridade, quanto menos instruído o informante, maior o índice de assimilação; no caso do sexo, os homens tendem a apagar mais que as mulheres.

Outro estudo variacionista realizado sobre o apagamento da oclusiva foi feito por Martins (2001), na comunidade de João Pessoa. Nesse trabalho, os resultados mostraram que o maior índice de apagamento da oclusiva dental /d/ deu-se entre os gerúndios. Os verbos no presente do indicativo (pretendo $\sim$ preteno) e a conjunção (quando quano), por outro lado, desfavoreceram a queda do segmento. Quanto à extensão do item lexical, os resultados revelaram que itens com mais de duas sílabas favoreceram o apagamento da oclusiva, em oposição aos vocábulos dissilábicos, que mantiveram o segmento.

No que se refere aos fatores sociais, os resultados também foram semelhantes aos apresentados no Rio de Janeiro. Os falantes masculinos tenderam a apagar com maior freqüência e os falantes com maior tempo de exposição à escola tenderam a correlacionar mais positivamente à presença da oclusiva dental, em oposição àqueles que possuem menos escolarização.

\section{METODOLOGIA}

Os dados para esta pesquisa foram extraídos de um corpus composto por registros de fala de 6 informantes residentes na região do Brejo Paraibano. As entrevistas, gravadas em situações naturais de interação social, foram realizadas com base em questões voltadas para os interesses de cada informante, de acordo com as informações contidas em uma ficha social, com perguntas pessoais, anteriormente aplicadas.

Após a aplicação da ficha social com os 6 informantes, foram elaborados questionários individuais e cada informante foi entrevistado durante cerca de 30 minutos.

Para a escolha destes informantes, foram observados os seguintes requisitos: i) ser natural da região do Brejo ou morar na região desde os cinco anos de idade; ii) nunca ter passado mais de dois anos consecutivos fora da região. Os informantes foram selecionados de forma aleatória e o corpus foi estratificado por sexo, com informantes entre 19 e 25 anos, de nível universitário.

Após esta primeira etapa metodológica, os dados coletados foram submetidos a um tratamento computacional, através do software GOLDVARB X, específico para pesquisas de sociolingüística quantitativa.

\section{CARACTERIZAÇÃo DAS VARIÁVEIS CONTROLADAS}

Com base em leituras realizadas para a pesquisa e observações parciais do corpus foram levantadas algumas hipóteses, relacionadas a algumas variáveis que merecem destaque diante do fenômeno estudado. 


\section{a) Classe de palavras}

Dentro desta variável, o intuito foi constatar se a hipótese de que as formas verbais de gerúndio são as mais afetadas pelo apagamento do /d/. Para esta finalidade, os itens lexicais foram ordenados da seguinte forma: 1. Substantivo comum: "ficou todo mundo aterrorizado" (SSS)3; 2. Conjunção: "foi quando eu ia" (HMPS); 3. Verbo no gerúndio: "vai conquistando dia-a-dia" (JS); 4. Verbo no presente do indicativo: "eu pretendo casar" (SCL).

\section{b) Extensão do vocábulo}

Em relação à extensão do vocábulo, a hipótese levantada foi a de que quanto maior o tamanho do vocábulo, maior seria a probabilidade de ocorrer o apagamento da oclusiva dental /d/. O fenômeno está relacionado com o número de sílabas, subdividido em três grupos: 1. Dissilabo: "tá sendo gravado" (SSS); 2. Trissílabo: "ficava lembrando da vida" (SSS); 3. Polissílabo: "me dedicando àquilo" (HMPS).

\section{c) Contexto fonético-fonológico seguinte}

Nesta variável, foram analisadas as palavras posteriores ao grupo "-ndo", com a finalidade de testar a hipótese de que há uma maior tendência de apagamento da oclusiva /d/ quando o elemento posterior tem traços fonético-fonológicos semelhantes. Esta variável foi dividida nos seguintes sub-fatores: 1. Pausa (\#): "de vez em quando \#" (CNL); 2. Consoante oclusiva /p, b, t, d, k, g/: "eu pretendo casar" (SCL); 3. Consoante fricativa /f, v, s, z, š, ž/: "não entendo futebol” (JMN); 4. Líquidas /1, r/: "todo mundo louco" (CNL); 5. Nasais /m, n/: "Programas envolvendo música” (HMPS); 6. Vogal central /a/: "andando aqui”" (SCL); 7. Vogais posteriores /u, ó, ô/: "continua sendo o Guarabira (time de futebol)" (SSS); 8. Vogais anteriores /i, é, ê/: "tô ensinando en um" (JMN).

d) Contexto fonético-fonológico anterior

Esta variável observa as vogais que se encontram no contexto precedente ao grupo "-ndo". A hipótese levantada foi a de que a vogal central favoreceria o apagamento do /d/. As vogais foram divididas da seguinte maneira: 1. Vogal central /a/: "caças arrasando toda a ilha" (HMPS); 2. Vogais anteriores médias /ê, é/: "eu pretendo me especializar" (SCL); 3. Vogal anterior alta /i/: "fiquei rindo" (JS); 4. Vogais posteriores médias /ô, ó/: não houve ocorrência no corpus levantado; 5 . Vogal posterior alta / u/: "segundo tempo" (JMN).

e) Anos de escolarização

Os falantes que compõem o corpus desta pesquisa se encontram no nível de escolarização que corresponde a mais de onze anos, ou seja, as entrevistas foram realizadas apenas com universitários. Vários trabalhos sociolingüísticos vêm mos-

3 Exemplos tirados do Corpus Lingüístico do Brejo da Paraíba. As siglas, em parênteses, abreviam os nomes dos informantes. 
trando que há uma tendência de as formas lingüísticas padrão prevalecerem em falantes com maior nível de escolarização. Baseado nesta premissa, espera-se um baixo índice de variantes não-padrão nesta pesquisa.

f) Sexo

Ainda com relação aos fatores sociais, foi levantada a hipótese de que o sexo feminino utiliza a forma de prestígio (isto é, a forma padrão) com mais freqüência do que o masculino, isto é, as mulheres apagam menos a oclusiva dental /d/. Diversos estudos sociolingüísticos consistentes confirmam a tendência de as mulheres serem mais conservadoras em relação à língua falada.

\section{g) Faixa etária}

O estudo da faixa etária em relação à língua pode fornecer subsídios para o entendimento do processo de variação em uma comunidade lingüística. Neste trabalho, os informantes se encontram em apenas uma faixa de idade, entre 19 e 25 anos, e se caracterizam como jovens que se iniciam no mercado de trabalho. A hipótese levantada é a de que, por sofrerem as pressões lingüísticas impostas pelo mercado de trabalho, os falantes tendam a um maior conservadorismo da língua padrão, isto é, à retenção da oclusiva dental /d/.

\section{APRESENTAÇÃO E ANÁLISE dOS RESULTADOS}

A seguir, são apresentadas as variáveis apontadas pelo programa computacional GOLDVARB X como relevantes para o fenômeno em estudo.

Ao término das rodadas do programa, foram detectadas 281 ocorrências do grupo "-ndo". Dessas ocorrências, 92 (32,7\%) foram de apagamento da oclusiva /d/, como em "pensano" e "gostano" e 189 (67,3\%) de manutenção do /d/. Este primeiro resultado já indica que os falantes universitários preferem a forma padrão da língua, o que corrobora a hipótese levantada nesta pesquisa.

Para se chegar às variáveis selecionadas como relevantes para o estudo em questão, a pesquisa passou por algumas etapas, que serão mencionadas a seguir. Numa primeira rodada dos dados, foram detectados três knock-outs, que é a não existência de variação em alguma variável. A ocorrência de knock-outs inviabiliza a continuação do programa computacional, por isso faz-se necessária a realização de amalgamações nos fatores que não apresentaram variação, para dar prosseguimento à execução do programa. Para solucionar os casos de knock-outs foram realizados os seguintes procedimentos:

a) No fator "Classe de palavras", foram observados dois knock-outs: substantivo comum e verbos, no presente do indicativo. Nestas duas classes não foi observado o apagamento do /d/, ou seja, os dados revelaram 100\% de aplicação do /d/ no grupo "-ndo". Os substantivos comuns somaram 41 ocorrências e os verbos no presente do indicativo, 9 ocorrências. Foram amalgamados, então, os fatores "conjunção" e "substantivo comum", resultando em um novo fator; da mesma 
forma, foram amalgamados "verbos no presente do indicativo" e "verbos no gerúndio". Dessa forma, o grupo ficou dividido da seguinte maneira: i) substantivo comum + conjunção; ii) verbo no gerúndio + verbo no presente do indicativo;

b) Na variável "Contexto fonético-fonológico anterior" também foi retirado da rodada o fator que revelou 100\% de aplicação da oclusiva dental /d/: as vogais altas posteriores, com 39 ocorrências. Como o grupo "-ndo" não apresentou variação quando o que o antecedeu foi uma vogal posterior alta, foram amalgamadas os sub-fatores "vogal anterior alta" e "vogal posterior alta".

Após as modificações acima e a solução de todos os casos de knock-outs, procedeu-se uma nova rodada dos dados. Desta vez, não foi observado nenhum caso de knock-out. Na rodada final dos dados, o programa selecionou como mais favoráveis ao apagamento do /d/, os seguintes fatores, listados em ordem de relevância: classe de palavras, sexo e contexto fonético-fonológico anterior.

As variáveis lingüísticas "extensão do vocábulo" e "contexto fonéticofonológico seguinte" foram consideradas, pelo software, como irrelevantes para o fenômeno do apagamento do /d/, portanto não serão analisadas neste trabalho. No estudo deste fenômeno, na comunidade do Rio de Janeiro, realizado por Mollica e Mattos (1989), a variável "contexto fonético-fonológico seguinte" também não foi considerada significativa, o que corrobora os dados desta pesquisa.

A seguir, serão apresentados os resultados e as análises das variáveis lingüísticas e sociais selecionadas.

\section{Classe de palavras}

O fator "Classe de palavras" foi o primeiro a ser selecionado pelo programa computacional. Assim como no estudo de Martins (2001) e no de Mollica e Matos (1989), é na categoria gramatical dos verbos onde ocorre o maior índice de apagamento do /d/ (61,2\%) na fala do Brejo da Paraíba. Na tabela 1, podemos ver os resultados do fator "Classe de palavras" na comunidade do Brejo da Paraíba.

No item "conjunção + substantivo", o índice de preservação do /d/ é bastante significativo. De fato, ele apresenta um peso relativo de 0,93 , que indica uma alta probabilidade de ocorrência da oclusiva dental. Conforme Mollica e Mattos (1989), há uma maior preservação do /d/ no grupo “-ndo” quando os vocábulos estão na sua forma primitiva, como nos nomes. No outro item gramatical (verbos), o apagamento ocorre em maior proporção (preservação apenas em 38,8\% dos casos). Portanto, conclui-se que o apagamento do /d/ ocorre com maior freqüência quando o grupo "ndo" faz parte de um sufixo; por outro lado, quando ele ocorre dentro da palavra (raiz), a preservação da oclusiva dental /d/ será maior. 
Tabela 1 - Presença da oclusiva / d/ no grupo "ndo" na variável Classe de palavras

\begin{tabular}{ccccc}
\hline Classe de palavras & Aplicação do “d” & Total & \% & P. R. ${ }^{4}$ \\
\hline $\begin{array}{c}\text { Conjunção + Subst. Co- } \\
\text { mum }\end{array}$ & 132 & 134 & $98,5 \%$ & 0,93 \\
Verbos & 57 & 147 & $38,8 \%$ & 0,07 \\
\hline
\end{tabular}

\section{Contexto fonético-fonológico anterior}

O contexto fonético-fonológico anterior leva em consideração as vogais que antecedem o grupo "ndo". A hipótese levantada a respeito da vogal central /a/ não correspondeu aos resultados encontrados, pois este fator se mostrou mais propenso à manutenção $(0,45)$ do que ao apagamento. No entanto, as vogais anteriores médias /ê, é/ surpreenderam dentro desta variável, ao apresentar peso relativo 0,71 .

A tabela abaixo mostra os resultados encontrados.

Tabela 2 - presença da oclusiva /d/ no grupo "ndo" na variável Contexto fonéticofonológico anterior

\begin{tabular}{ccccc}
\hline Fatores & Aplicação do “d” & Total & \% & P. R. \\
\hline /a/ & 121 & 184 & $65,8 \%$ & 0,45 \\
/ê/, /é/ & 23 & 41 & $56,1 \%$ & 0,71 \\
/i/, /u/ & 45 & 56 & $80,4 \%$ & 0,48 \\
\hline
\end{tabular}

Pelo que se pode perceber pela tabela 2 , as vogais altas $(/ \mathrm{i} /, / \mathrm{u} /)$ favorecem a manutenção da oclusiva dental, com um percentual de $80,4 \%$, seguidas da vogal central $(65,8 \%)$ e das vogais médias (/ê/, /é/) (56,1\%). Uma explicação para isso poderia ser pelo fato de a vogal alta /i/ ter o traço fonológico [coronal], compartilhado pela oclusiva dental /d/, também coronal.

Sexo

O fator sexo foi a única variável social selecionada (a segunda em ordem de importância) pelo programa GOLDVARB X. Diversos estudos sociolingüísticos apontam a variável sexo como um dos fatores condicionantes da heterogeneidade lingüística, indicando que homens e mulheres possuem, de fato, comportamento lingüístico distinto.

A variável sexo vem se mostrado relevante não apenas com relação ao estudo do apagamento da oclusiva /d/, mas também em vários outros fenômenos e em outras comunidades de fala. Silva \& Paiva (1996, p. 362) afirmam que há uma

4 P.R.: Peso Relativo 
forte propensão de as mulheres utilizarem as formas lingüísticas padronizadas, seja em fenômenos de variação estável, seja nos de mudança.

Há também autores que defendem que a maior freqüência de utilização da forma padrão pelas mulheres é para evitar associações estigmatizadas com estereótipos da classe inferior ou como forma de manutenção de status social, como afirma Gordon (apud MARTINS, 2004).

$\mathrm{Na}$ tabela abaixo, é possível observar os resultados da variável sexo no Brejo da Paraíba:

Tabela 3 - Presença da oclusiva / d/ no grupo "ndo" na variável sexo

\begin{tabular}{ccccc}
\hline Fatores & Aplicação do "d" & Total & \% & P. R. \\
\hline Masculino & 86 & 137 & $62,8 \%$ & 0,36 \\
Feminino & 103 & 144 & $71 \%$ & 0,62 \\
\hline
\end{tabular}

A partir dos dados da tabela acima, pode-se perceber que há uma maior preservação do /d/ pelos informantes do sexo feminino $(0,62)$, ao contrário dos homens $(0,36)$. Os homens se mostraram mais propensos à utilização da forma nãopadrão, como em: "tô gostano bastante" ou "o que está aconteceno na atualidade". O resultado com relação à variável sexo no Brejo da Paraíba confirma os resultados obtidos por Mollica e Mattos (1989) e Martins (2004).

Os resultados aqui observados, portanto, confirmam a hipótese inicial de que falantes do sexo feminino utilizam a forma de prestígio com maior freqüência do que os do sexo masculino.

\section{CONCLUSÃo}

Através desta pesquisa, foi possível descrever o comportamento lingüístico dos falantes jovens e universitários na região do Brejo da Paraíba, sob o ponto de vista da sociolingüística variacionista.

Vale salientar que o apagamento não é encarado aqui associado ao uso indevido da língua. Pelo contrário, buscou-se mostrar este fenômeno como uma alternativa de expressão na língua portuguesa oral. Como visto, o apagamento é um fenômeno de variação que sofre a influência de fatores lingüísticos e extralingüísticos. Dentro dos fatores lingüísticos e sociais examinados, os considerados mais relevantes pelo programa computacional GOLDVARB X foram:

a) Classe de palavras: na variável "classe de palavras", os resultados mostraram que é no fator "verbo" que ocorre o maior índice de apagamento do /d/ no grupo "ndo". Já o fator que compreende os substantivos comuns e conjunção revelou uma tendência a reter a dental sonora em maior proporção. 
b) Contexto fonético-fonológico anterior: nesta variável, os dados mostraram que as vogais altas favorecem a manutenção da oclusiva dental. Como já foi mencionado, uma explicação para isso poderia ser pelo fato de a vogal alta /i/ ter o mesmo traço fonológico que a oclusiva dental /d/: o traço de coronalidade.

c) Sexo: com relação à variável social "sexo", as hipóteses lançadas foram confirmadas, pois os resultados mostraram que os homens tendem a uma maior freqüência a apagar a oclusiva dental /d/, em comparação aos falantes femininos.

Através destes resultados, é possível avaliar a função que estas variáveis exercem sobre o apagamento da oclusiva dental $/ \mathrm{d} /$.

O fenômeno do apagamento da oclusiva /d/ no grupo "ndo" no Brejo da Paraíba ocorreu em menor proporção, dando mais espaço para a preservação do /d/, devido ao fato de o corpus da pesquisa ser constituído por falantes universitários. Apesar disto, o fato de o apagamento do /d/ também estar presente na fala dos universitários mostra que não se trata de uma variação estigmatizada.

Para que esta pesquisa tenha resultados mais abrangentes faz-se necessário uma amplificação do corpus. Dessa forma, será possível analisar se o fenômeno em estudo caracteriza-se como uma variável estável ou se é uma variação em mudança.

A semelhança dos resultados obtidos nesta pesquisa com outros trabalhos realizados na cidade de João Pessoa e no Rio de Janeiro atesta que o fenômeno do apagamento/manutenção da oclusiva dental /d/, mais do que um fenômeno restrito a uma área específica do país, tem um caráter abrangente. Sendo um fenômeno nacional, espera-se que esta pesquisa realizada no Brejo da Paraíba possa contribuir para ampliar o conhecimento do português falado no Brasil.

\section{REFERÊNCIAS}

MARTINS, Iara Ferreira de M. Apagamento da oclusiva dental / d/ no grupo "ndo" na fala de João Pessoa. Dissertação (Mestrado em Letras). - Universidade Federal da Paraíba, 2001.

MARTINS, Iara Ferreira de M. Apagamento da oclusiva dental /d/: perspectivas variacionistas e fonológicas. In: HORA, Dermeval. Estudos sociolingüisticos: perfil de uma comunidade. Santa Maria: Pallotti, 2004.

MELO, Gladstone Chaves de. A lingua do Brasil. Rio de Janeiro: Agir, 1946.

MOLICA E MATTOS, Paula B. Dois processos de assimilação fonológica no português falado semiespontâneo do Rio de Janeiro. Dissertação (Mestrado). - Universidade Federal do Rio de Janeiro, 1989.

SILVA NETO, Serafim da. História da língua portuguesa. 2. ed. Rio de Janeiro: Livros de Portugal, 1970.

SILVA, Giselle M. de Oliveira; PAIVA, Maria da Conceição A. Visão de conjunto das variáveis sociais. In: SILVA, Giselle M. de Oliveira; SCHERRE, Maria Marta P. Padrões sociolingüísticos. Rio de Janeiro: Tempo Brasileiro, 1996. 
